\title{
A saúde mental dos adultos durante o isolamento social no decorrer da pandemia da Covid-19
}

Adult mental health during social isolation during the Covid-19 pandemic

Salud mental de adultos durante el aislamiento social durante la pandemia de Covid-19

Carolina Borba Freire ${ }^{1 *}$, Laura Menezes de Carvalho Cruz², Ana Beatriz Alves Souza e Souza ${ }^{1}$, Ana Luísa Passos Uzêda Luna ${ }^{3}$, Lorena Leite Pereira ${ }^{3}$, Ludimila Brito Batista ${ }^{4}$, Isabella Maria Gonçalves de Oliveira ${ }^{4}$, Ana Luiza Neves Brito ${ }^{4}$, Victoria Barbosa Mendes Veloso ${ }^{4}$, Roberto Botelho e Silva1.

\section{RESUMO}

Objetivo: Compreender as repercussões da pandemia da covid-19 na saúde mental dos adultos, durante o período de isolamento social. Revisão bibliográfica: O distanciamento social adotado para reduzir a infecção pelo SARS-CoV-2 provocou grandes mudanças no dia a dia, na economia e nas relações entre as pessoas. Além disso, a rotina dos indivíduos mudou durante o período de isolamento social levando a problemas do sono, apetite, conflitos familiares, uso de drogas lícitas e ilícitas, assim podendo desencadear ou agravar os transtornos de ansiedade e depressão. Durante a pandemia e consequentemente com o isolamento social, é natural que haja uma desordem emocional e psíquica na população, agravando sintomas de compulsão alimentícia, bem como ansiedade e depressão. Considerações finais: Assim, por meio da instauração da pandemia, é possível averiguar a desestruturação da população frente ao quadro, acompanhando assim o aumento na incidência e prevalência dos transtornos mentais no decorrer da pandemia do coronavírus.

Palavras-chave: Saúde mental, Isolamento social, Pandemia, Covid-19.

\begin{abstract}
Objective: To understand the repercussions of the covid-19 pandemic on the mental health of adults, during the period of social isolation. Bibliographic review: The social distancing adopted to reduce SARS-CoV-2 infection has brought about major changes in daily life, in the economy and in the relationships between people. In addition, the routine of individuals changed during the period of social isolation, leading to sleep problems, appetite, family conflicts, use of licit and illicit drugs, thus being able to trigger or worsen anxiety and depression disorders. During the pandemic, it is natural to increase symptoms of anxiety and depression, which are risk factors for emotional hunger and compulsive eating that are very prevalent among individuals who are overweight. Final considerations: Thus, through the establishment of the pandemic, it is possible to verify the disruption of the population in the face of the situation, thus accompanying the increase in the incidence and prevalence of mental disorders during the coronavirus pandemic.
\end{abstract}

Key words: Mental health, Social isolation, Pandemic, Covid-19.

\footnotetext{
${ }^{1}$ Faculdade Santo Agostinho (FASA), Vitória da Conquista - BA. *E-mail: carolbfreire@outlook.com

${ }^{2}$ Faculdade Santo Agostinho de Itabuna (FASAI), Itabuna - BA.

3 União Metropolitana de Educação e Cultura (UNIME), Lauro de Freitas - BA.

${ }^{4}$ Faculdades Integradas do Norte de Minas (FUNORTE), Montes Claros - MG.
}

SUBMETIDO EM: 2/2022

ACEITO EM: 2/2022

PUBLICADO EM: 2/2022 


\section{RESUMEN}

Objetivo: Comprender las repercusiones de la pandemia de covid-19 en la salud mental de los adultos, durante el período de aislamiento social. Revisión bibliográfica: El distanciamiento social adoptado para reducir el contagio por SARS-CoV-2 ha provocado grandes cambios en la vida cotidiana, en la economía y en las relaciones entre las personas. Además, la rutina de los individuos cambió durante el período de aislamiento social, lo que generó problemas de sueño, apetito, conflictos familiares, uso de drogas lícitas e ilícitas, pudiendo desencadenar o empeorar los trastornos de ansiedad y depresión. Durante la pandemia, es natural que aumenten los síntomas de ansiedad y depresión, que son factores de riesgo para el hambre emocional y la alimentación compulsiva muy prevalentes entre las personas con sobrepeso. Consideraciones finales: Así, a través del establecimiento de la pandemia, es posible verificar la disrupción de la población frente a la situación, acompañando así el aumento de la incidencia y prevalencia de los trastornos mentales durante la pandemia del coronavirus.

Palabras clave: Salud mental, Aislamiento social, Pandemia, Covid-19.

\section{INTRODUÇÃO}

A descrição do primeiro coronavírus se deu no ano de 1965, devido a um estudo experimental na qual verificou que este vírus era capaz de ocasionar quadros de resfriados em humanos. No ano seguinte o mesmo vírus foi isolado e assim recebeu o nome de HCoV229E. Em 1967, outro vírus foi isolado e recebeu o nome de HCoV-OC43 para avaliação quanto a sua relação com o resfriado. Neste mesmo ano, pode se constatar que estas duas cepas pertenciam ao mesmo grupo de vírus e assim foi criada em 1975 a família Coronaviridae (MARTIN OS, et al., 2020)

De início o vírus apresentava apenas infecções de perfis considerados leves e moderados. Assim, em meados do ano de 2002, na China, que a Síndrome Respiratória Aguda Grave (SARS) surgiu tendo como causador um coronavírus até então desconhecido, denominando-se SARS-CoV. Esse vírus gerou uma situação de epidemia causando um total de 774 mortes e tendo como reservatório natural um pequeno carnívoro conhecido como Civeta (GRENDENE CS, et al., 2021).

Após o surgimento da SARS, numerosos casos de coronavírus foram descritos sempre se relacionando a quadros de infecções respiratórias, sejam elas altas ou baixas. A maioria dos casos sendo leves, cerca de $80 \%$, que podem evoluir para quadros graves de insuficiência respiratória, em torno de $5 \%$ a $10 \%$ dos casos, principalmente aqueles relacionados a fatores de risco como: Doença Pulmonar Obstrutiva Crônica (DPOC), Obesidade, Hipertensão Arterial Sistêmica (HAS), Diabetes Mellitus (DM), Doença Arterial Coronariana (DAC) e Insuficiência Cardíaca (IC) (FAVRETTO IC, et al., 2021)

Por conseguinte, em 2012, ocorreu na região do Oriente Médio um surto relacionado ao coronavírus denominado Síndrome respiratória do Oriente Médio (MERS) com quadro de uma nova infecção respiratória grave que deixou um total de 866 óbitos. No entanto, em dezembro de 2019, a China apresentava novos casos de pneumonia que tiveram origem a partir de uma nova cepa de coronavírus, até então, ainda não identificadas em seres humanos. Na atualidade essa nova cepa, assim como as sete na qual já se há conhecimento da existência, tem como causa a SARS (CEVIK M, et al., 2021).

Com o novo quadro trazido pela Covid-19 o mundo entrou em colapso de diversos extremos: tanto político, econômico e quanto o da própria saúde. A rápida proliferação de notícias falsas, sensacionalistas e sem embasamento científico possuem um efeito nocivo à saúde mental da população, uma vez que geram ainda mais incertezas e desinformam os indivíduos (RIBEIRO MM, et al., 2021).

A Organização Mundial de Saúde (OMS) designa saúde mental como uma condição de bem-estar no qual o indivíduo é considerado capaz de exercer suas habilidades, tornou-se passiva de efeitos deletérios, em decorrência de mudanças de comportamento, pensamentos e de emoções de forma abrupta, as quais propiciaram o surgimento e aumento de prevalência de doenças mentais. O medo de contrair a Covid-19 desencadeou na população de modo geral inseguranças em todos os aspectos da vida e do funcionamento diário da sociedade (GAINO LV, et al., 2018). 
Desse modo, teve-se um aumento dos sintomas psíquicos e dos transtornos mentais trazidas pela pandemia como por exemplo: a depressão, a ansiedade, o medo da morte ou de perder alguém próximo, as alterações de sono, as frustações, a irritabilidade, a preocupação, o sentimento de impotência, o humor rebaixado e o estresse (DALDEGAN N, et al., 2021).

As consequências para a saúde mental relatadas nas tragédias anteriores tiveram impacto psicossocial de forma incalculável e chegaram a durar mais do que a pandemia em si. Lamentavelmente, com o avanço da pandemia número de afetados pela doença foi superado pelo número de pessoas que desenvolveram transtornos mentais. No início da pandemia do Covid-19, um levantamento on-line foi feito por autores como Lipp MEN e Lipp LMV (2020), demostrando que 1.468 adultos que trabalhavam de forma presencial ou pertenciam a um grupo de risco ou com idosos tiveram altas taxas de stress relatadas durante o período de março no Brasil.

Em outros estudos, a disseminação de informações obtidas nas redes sociais, gerou grande estresse na população jovem de faixa etária entre 18 a 30 anos. Nesse estudo $35 \%$ das pessoas entrevistadas em um grupo de 53.730 apresentaram problemas psíquicos, sendo que o sexo feminino apresentou maior sofrimento psíquico comparado ao do sexo masculino na China durante o período de janeiro a fevereiro de 2021 (SILVA HGN, et al., 2020).

Assim, esse constructo teve como objetivo compreender por meio de uma revisão sobre as repercussões da pandemia da Covid-19 na saúde mental dos adultos, durante o período de isolamento social.

\section{REVISÃO BIBLIOGRÁFICA}

Em 2019, o mundo foi surpreendido com uma nova doença causada pelo vírus SARS-CoV-2, na qual teve seu primeiro caso reportado na China, na cidade de Wuhan no início de dezembro de 2019. A Covid-19 é um vírus zoonótico, um RNA vírus envelopado, da família Coronaviridae, capaz de causar doenças respiratórias graves. Em janeiro de 2020 se tornou uma emergência de saúde pública a nível internacional e com disseminação a nível global. Em março de 2020, a Organização Mundial da Saúde (OMS) caracterizoua como pandemia. Em 3 de abril de 2020, 206 países registravam infecções pelo novo coronavírus, com o total de 976.249 casos confirmados e 50.489 mortes (FERRER R, 2020).

Alguns países para combater os agentes patogênicos e contribuir para a saúde física das pessoas que são os focos primários da atenção de saúde adotaram medidas de isolamento social em casos suspeitos, fechamento de instituições como escola e universidade, além de priorizar o distanciamento social principalmente de idosos e indivíduos que são considerados grupos de risco, bem como, a importância da quarentena para população em geral, para com assim reduzir os impactos da pandemia, seu pico de incidência e o número de mortes (ZANDIFAR A e BADRFAM R, 2020).

Por conseguinte, a disseminação do novo coronavírus e o tempo de duração da pandemia trouxeram consigo fatores de risco à saúde mental da população. Visto que, as incertezas acerca do controle da doença, bem como a imprevisibilidade em relação ao tempo de permanência do isolamento afetou de forma direta questões de cunho emocional e psíquico. Devido ao pouco conhecimento sobre o curso e origem dessa patologia trouxeram um medo significante da população para com o vírus, devido ao seu alto potencial infectante e sua rápida disseminação, gerando assim determinada influencia no bem-estar psicológico das pessoas. As inserções dos isolamentos sociais repercutiram negativamente na manutenção da saúde mental da população, houve um aumento dos transtornos psíquicos evidenciando quadros de depressão, ansiedade e estresse diante da pandemia (SCHMIDT B, et al., 2020).

Com os impactos psicológicos acometidos pela Covid-19 acarretaram em um aumento progressivo nos casos de suicídio já reportados. Com a vasta onda de informações pessoas começaram a desenvolver sintomas obsessivos e compulsivos para tentar sanar ou impedir o avanço da infecção, como limpeza excessiva, verificação de temperatura diária, limpeza de alimentos naturais. Desde o surgimento da pandemia do novo coronavírus começou, a preocupação com a higienização das mãos e de casa foi redobrada e muitos acabaram que pelo medo tornando isso um vício compulsório desencadeando assim 0 Transtorno Obsessivo Compulsivo (TOC) (BAO Y, et al., 2020). 
A ansiedade em relação à pandemia se tornou um dos transtornos mais persistentes nesse período. A preocupação exacerbada por não saber com que estamos lhe dando em relação ao vírus e seus sintomas gerou um conflito entre os dois quadros, devido seus quadros serem bem similares com a presença de falta de ar, dificuldade para respirar ou sensação de aperto no peito. A população assim vive uma crise ansiosa com este cenário imposto capaz de provocar equivoco das próprias sensações corporais gerando uma confusão entre SARS- CoV-2 e um transtorno ansioso e estas por suas vezes com medo se direcionam aos serviços de saúde em busca de melhora, conforme o ocorrido na pandemia de 2009, ocasionada pela influenza (ASMUNDSON GJG e TAYLOR S, 2020).

Com o fechamento das escolas e universidades, isolamento de idosos e outros grupos de risco devido a medidas de proteção ocasionadas pela quarentena, permitiu que outro fator estressor fosse instalado, ou seja, o do próprio distanciamento entre pessoas, na qual a interação entre social se tornou um desafio por tudo ser possível durante este período Vale ressaltar desde que a pandemia do novo coronavírus começou, a preocupação com a higienização das mãos e de casa foi redobrada e muitos acabaram que pelo medo tornando isso um vício compulsório desencadeando assim o TOC (BAO Y, et al., 2020).

A sobrecarga gerada entre os profissionais de saúde se tornaram experiências estressoras para 0 mesmo sabendo que carregam grandes responsabilidades ao se tratar da saúde de outro indivíduo e de se próprio. Para eles, o risco de se infectar aumenta, de adoecer e da morte, a ausência da família e amigos, a sobrecarga do serviço são frustações diárias e recorrentes em meio ao seu mundo (ANJOS KF e SANTOS VC, 2020).

A pandemia permitiu que novos desafios fossem traçados inclusive pelos profissionais de saúde presentes na linha de frente do covid-19, cuidando de pessoas infectadas pelo vírus. A saúde destes profissionais se tornou algo preocupante com o aumento considerável do nível de estresse, crises de ansiedades, depressão, devido às incertezas do amanhã (FLORENTINO AO, et al., 2021).

O SARS-CoV 2 permitiu com que um a compulsão alimentar acompanhasse a população em períodos de pandemia. O distanciamento social provocou as mudanças em todos os âmbitos e o alimentar também não ficou de fora. Mais tempo em casa contribui para melhoria e piora dos hábitos alimentares, justificáveis pelo isolamento social. Ao se tornar refém em suas próprias residências, pessoas optaram por seguir uma rotina saudável, estes grupos começaram a treinar em casa e se fazer uma reeducação alimentar, já que com a correria do trabalho antes não se era feito. A alimentação passou a ser baixa em carboidratos e passaram a ser ricas em proteínas e leguminosas tornando assim como o exercício algo positivo para com o sistema imunológico. Mas ao mesmo tempo outro grupo acabou vendo o isolamento como algo prejudicial, o tempo preso em cassa permitiu que aumentasse o tempo de uso com aparelhos eletrônicos e esquecessem da realidade, se tornando indivíduos sedentários e optando sempre por se alimentar de alta praticidade como os industrializados, aumentando assim sua ingesta calórica diária devido justamente aos tempos de incerteza vivenciada por toda população mundial (MALLOY-DINIZ LF, et al., 2020).

Durante a pandemia, é natural o aumento de sintomas de ansiedade e depressão, que são fatores de risco para a fome emocional e o comer compulsivo muito prevalente entre os indivíduos que possuem excesso de peso. Para a piora do prognostico do Covid-19, a obesidade entrou como um fator já esperado para o aumento do seu risco (SOUZA AAF e DUNNINGHAM WA, 2019).

Além dos fatores sociodemográficos, que determinam de forma muito importante o consumo alimentar, o estágio do surto, pré, inicial ou final, e a percepção da gravidade da doença também impactam 0 comportamento dos indivíduos. Diante desse quadro pandêmico, os indivíduos têm tomado medidas para se protegerem, aderindo às diretrizes oficiais de segurança delineadas por órgãos governamentais e de saúde pública, que incluem distanciamento social, uso de máscaras faciais, prática de higiene adequada e manutenção de outros comportamentos preventivos (STORCH EA, et al., 2021).

No que diz respeito sobre a higiene das mãos, o medo da contaminação gerou aumento do nível de estresse em indivíduos acarretou em uma elevação nos sintomas psíquicos principalmente aqueles com transtorno compulsivo, seja naqueles que já tenham a doença ou nos que contem a doença como préexistente. (MATSUNAGA H, et al., 2020). Nesse contexto, para Ornell F, et al. (2021), o risco iminente de contaminação cria uma necessidade lógica de autovigilância e hábitos de higiene. 
No entanto, esse tipo de informação pode ter implicações drásticas para sujeitos com TOC, especialmente aqueles que têm obsessão por contaminação e compulsão por lavar, uma vez que distorções cognitivas e estratégias compensatórias (rituais de limpeza) não são mais irracionais ou superdimensionadas, ao contrário, essas ideias tornam- se necessárias, legítimas e socialmente aceitas, gerando validação plausível para a intensificação da compulsão e rituais de limpeza, como descrito por (SILVA LGC e MAIA JLF, 2021).

Neste quadro alastrante da pandemia, a população estagnou em um imenso período de isolamento social, na qual um estudo comprovou impacto na saúde mental, física, neurológica e psicológica de 1.210 participantes, que demonstraram sintomas moderados a severos de quadros de ansiedade, depressão e estresse, sendo que destes 75,2 relataram medo de seus familiares contraírem a doença desencadeando impactos na saúde. (STORCH EA, et al., 2021).

Em contrapartida, com a condição pandêmica instaurada e a convivência com o novo normal, mostra que quarentena trouxe um aumento dos transtornos mentais, devido a uma grade de incertezas, medo da doença, medo de morte e aumento do nível de ansiedade (NEUFELD CB, et al., 2021). Com as consequências do distanciamento social a passou a lidar com o alto risco de infecção pelo vírus, com a possibilidade de perder familiares e amigos, com a diminuição da renda ou desemprego, entre outras incertezas, que aumentaram sentimento de tristeza, ansiedade, medo, preocupação, frustração e estresse entre a população (BEZERRA CB, et al., 2020).

Como por exemplo os profissionais de saúde que atuam na linha de frente no combate à Covid-19. Eles enfrentam longos turnos de trabalho com grande volume de pacientes e, ao mesmo tempo, lidam com a complexidade dos casos da Covid-19. A Escassez de suprimentos, inclusive equipamentos de proteção individual (EPIs), somam-se aos fatores estressores do trabalho, o distanciamento dos entes queridos e os demais impactos da pandemia. As principais consequências identificadas nessa população foram sensação de sobrecarga, insônia, uso abusivo de substâncias e sentimento de culpa, medo, raiva, tédio, tristeza, frustração e ansiedade (TEIXEIRA CFS, et al., 2020).

Pais e professores também podem ser considerados grupos especialmente vulneráveis aos impactos da pandemia. Os professores se viram obrigados a executar o ensino remoto de forma abrupta, muitas vezes, sem a formação adequada para tal, levando a altos níveis de desgaste e estresse. Além disso, enfrentam redução de salário, suspensão e/ou redução do contrato de trabalho e aumento da carga horária e, ainda, sofrem pressão da sociedade para o retorno às atividades presenciais mesmo com a precariedade de estudos acerca dos impactos sobre a saúde desses trabalhadores. Todos esses fatores podem desencadear sintomas de ansiedade e de angústia (CÉNAT JM, et al., 2021).

Destaca-se também que essas preocupações são adicionais aos problemas já enfrentados pela população em geral advindos da pandemia e do distanciamento social (SILVA LGC e MAIA JLF, 2021). Já os pais passaram a conciliar a supervisão dos filhos e a rotina escolar desses com o trabalho home office ou presencial. Tais mudanças na rotina geraram sentimentos de preocupação com a saúde mental dos filhos, dificuldade para manejar as ferramentas tecnológicas do ensino remoto, dificuldades de lidar com a nova rotina, entre outros, resultando também em níveis altos de estresse e de ansiedade. Diante desse cenário, tornou-se urgente discutir e propor estratégias para prevenção e promoção em saúde mental adaptadas ao contexto (GROSSI MGR, et al., 2020).

Além disso, a rotina dos indivíduos mudou durante o período de isolamento social levando a problemas do sono, apetite, conflitos familiares, uso de drogas lícitas e ilícitas, assim podendo desencadear ou agravar os transtornos de ansiedade e depressão. Ademais, cada faixa etária se comporta de uma forma, por exemplo, os idosos principalmente aqueles que tem um domínio cognitivo diminuído, podem apresentar mais alterações emocionais. Já as crianças podem começar a presentar comportamentos que já não tinham mais, como querer voltar a dormir com os pais, chupar os dedos e urinar na cama (LIMA RC, 2020).

As pessoas no decorrer da pandemia começaram a desenvolver estresse pós-traumático, sintomas de irritabilidade e evitativos, além de passarem mais tempo sozinhas o que pode colaborar para transtornos mentais, principalmente depressão e ansiedade. $O$ fato de passarem mais tempo em redes sociais e vendo 
noticiários que muitas vezes são Fake News e deveras sem fundamento cientifico podendo colaborar com insegurança e angústia. A perda de um ente querido outro um membro familiar se tornou um fator que deve ser levado em consideração por não poder se despedir da melhor forma já que a quarentena impossibilitou este encontro, fazendo com que o luto seja ainda mais difícil. Com isso, podendo gerar pensamentos ruminativos, de ressentimento por não poder se despedir, insônia, depressão e mais isolamento (VERZTMAN J e ROMÃO-DIAS D, 2020).

Em relação aos sintomas mais relatados pela população brasileira a depressão atingiu $40 \%$, ansiedade $50 \%$, além disso, $40 \%$ das pessoas passaram a ter problemas de insônia. A ansiedade pode ser caracterizada com sinais e sintomas de tensão muscular, preocupação excessiva, principalmente com o futuro, sentimento de alerta, medo constante de que algo ruim pode acontecer, dificuldade de concentração e nervosismo. Assim, a pandemia agravou ainda mais os transtornos de ansiedade, por ser algo novo e incerto, a maioria das pessoas tiveram a rotina alterada, passando a ficar mais tempo em casa. Além do medo de contrair a doença que gera ainda mais sintomas de ansiedade (ROLIM JÁ, et al., 2020).

O número de casos de depressão aumentou muito na última década, atualmente acometendo quase $5 \%$ da população mundial. Infelizmente esse transtorno se agravou e que se manifestou ainda mais com a pandemia. A depressão pode ser definida como tristeza profunda, podendo ser associados a sensação de amargura, desesperança, baixo autoestima, alterações do apetite e sono. Com o passar dos meses o número de empregos diminuíram, levando a uma menor renda familiar, com isso, contribuindo para os pensamentos de incertezas e medo de não conseguir pagar as contas. Além disso, com os casos de covid19 só aumentando foram necessárias medidas de isolamento social e tiveram que postergar encontros, assim, as pessoas começaram a ficar mais tempo sozinhas em casa, contribuindo para sintomas de tristeza e solidão (NABUCO G, et al., 2020).

\section{CONSIDERAÇÕES FINAIS}

A pandemia colaborou para a piora e o desenvolvimento de problemas mentais, físicos, sociais e econômicos na população. Além disso, a pandemia tem contribuído para altos níveis de estresse, ansiedade, depressão e medo. Assim, por meio da instauração da pandemia, é possível averiguar a desestruturação da população frente ao quadro, acompanhando assim o aumento na incidência e prevalência dos transtornos mentais no decorrer da pandemia do coronavírus. Mas, o verdadeiro impacto na saúde mental das pessoas relacionadas ao covid-19 demandará tempo, já que a as manifestações psicológicas tem grande relação com períodos pós pandemia também. Desse modo, trabalhos como este visam possibilitar a reflexão sobre a importância dessa temática para que mais estudos sejam realizados, já que é um tema ainda novo.

\section{REFERÊNCIAS}

1. ASMUNDSON GJG, TAYLOR S. Coronaphobia: Fear and the 2019- nCoV outbreak. Journal of Anxiety Disorders, 2020; 70: e102196.

2. ANJOS KF, SANTOS VC. Transtorno de estresse pós-traumático no contexto da covid-19. Revista Brasileira de Saúde Funcional, 2020; 11(1): 6-6.

3. BAO Y, et al. 2019-nCoV epidemic: Address mental health care to empower society. The Lancet, 2020; 395(10224): 37-38.

4. BEZERRA CB, et al. Impacto psicossocial do isolamento durante pandemia de covid-19 na população brasileira: análise transversal preliminar. Saúde e Sociedade, 2020; 29(4): e200412.

5. CÉNAT JM, et al. Prevalence of symptoms of depression, anxiety, insomnia, posttraumatic stress disorder, and psychological distress among populations affected by the COVID-19 pandemic: a systematic review and metaanalysis. Psychiatry Research, 2021; 295: e113599.

6. CEVIK M, et al. Dinâmica da carga viral do SARS-CoV-2, SARS-CoV e MERS-CoV, duração da disseminação viral e infecciosidade: uma revisão sistemática e meta-análise. O micróbio da lanceta, 2021; 2(1): 13-22.

7. DALDEGAN N, et al. Ansiedade e depressão no contexto da pandemia de COVID-19. Revista Extensão \& Sociedade, 2021; (12)1. 
8. FERRER R. Pandemia de COVID-19: o maior desafio da história dos cuidados intensivos. Medicina Intensiva, 2020; 44(6).

9. FLORENTINO AO, et al. Estratégias para a melhoria no fluxo de atendimento aos casos suspeitos de COVID-19. Global Academic Nursing Journal, 2021; 2(2): 120-120.

10. FAVRETTO IC, et al. Fatores de risco associados ao acometimento pela COVID-19 em pacientes oncológicos: uma revisão sistemática. Revista de Saúde Pública do Paraná, 2021; 4(2): 125-139.

11. GROSSI MGR, et al. Impacto da pandemia do COVID-19 na educação: reflexos na vida das famílias. Teoria e Prática da Educação, 2020; 23(3): 150-170.

12. GAINO LV, et al. O conceito de saúde mental para profissionais de saúde: um estudo transversal e qualitativo*. SMAD, Rev. Eletrônica Saúde Mental Álcool Drog., 2018; 14(2): 108-116.

13. GRENDENE CS, et al. Coronavírus (covid-19): história, conhecimento atual e sequelas de longo prazo. Revista Corpus Hippocraticum, 2021; 1(1).

14. LIMA RC. Distanciamento e isolamento sociais pela Covid-19 no Brasil: impactos na saúde mental. Physis: Revista de Saúde Coletiva, 2020; 30(2).

15. LIPP MEN, LIPP LMV. Stress e transtornos mentais durante a pandemia da covid-19 no Brasil. Boletim Academia Paulista de Psicologia, 2020; 40(9): 180-191.

16. MARTIN OS, et al. História e Epidemiologia da COVID-19. Ulakes Journal Of Medicine, 2020; 1: 11-22.

17. MALLOY-DINIZ LF, et al. Saúde mental na pandemia de Covid-19: considerações práticas multidisciplinares sobre cognição, emoção e comportamento. Debates em Psiquiatria, 2020; 10(2):46-68.

18. MATSUNAGA H, et al. Acute impact of COVID -19 pandemic on phenomenological features in fully or partially remitted patients with obsessive-compulsive disorder. Psychiatry and Clinical Neurosciences, 2020; 74(10): 565-566.

19. NABUCO G, et al. O impacto da pandemia pela COVID-19 na saúde mental: qual é o papel da Atenção Primária à Saúde?. Rev Bras Med Fam Comunidade, 2020; 15(42): 2532.

20. NEUFELD CB, et al. LaPICC contra COVID-19: Relato de uma experiência de terapia cognitivo-comportamental em grupo online. Psico, 52(3): e41554.

21. ORNELL F, et al. Obsessive-compulsive disorder reinforcement during the COVID-19 pandemic. Trends in Psychiatry and Psychotherapy, 2021; 43(2).

22. RIBEIRO MM, et al. Administração política do capitalismo contemporâneo: desafios para o enfrentamento das crises sociais e econômicas provocadas pela pandemia da covid-19. Gestão \& Planejamento-G\&P, 2021; 22(1).

23. ROLIM JÁ, et al. Manejo da ansiedade no enfrentamento da Covid-19. Revista Enfermagem e Saúde Coletiva (REVESC), 2020; 5(1): 64-74.

24. SHIGEMURA J, et al. Public responses to the novel 2019 coronavírus (2019-nCoV) in Japan: mental health consequences and target populations. Psychiatry Clin Neurosci., 2020; 74(4): 281-282.

25. SILVA HGN, et al. Efeitos da pandemia no novo Coronavírus na saúde mental de indivíduos e coletividades. J. nurs. Health, 2020; 10: e20104007.

26. SCHMIDT B, et al. Saúde mental e intervenções psicológicas diante da pandemia do novo coronavírus (COVID-19). Estudos de Psicologia, 2020; 37: e200063.

27. SOUZA AAF, DUNNINGHAM WA. A Pandemia da Depressão. Revista Brasileira de Neurologia e Psiquiatria, 2019; 23(3).

28. STORCH EA, et al. Impact of the COVID-19 pandemic on exposure and response prevention outcomes in adults and youth with obsessive-compulsive disorder. Psychiatry Research, 2021;295: e113597.

29. SILVA LGC, MAIA JLF. Transtorno obsessivo-compulsivo na pandemia de COVID-19. Pesquisa, Sociedade e Desenvolvimento, 2021; 10(5): e59010515921.

30. TEIXEIRA CFS, et al. A saúde dos profissionais de saúde no enfrentamento da pandemia de Covid-19. Ciência \& Saúde Coletiva, 2020; 25(9): 3465-3474.

31. VERZTMAN J, ROMÃO-DIAS D. Catástrofe, luto e esperança: o trabalho psicanalítico na pandemia de COVID-19. Revista latinoamericana de psicopatologia fundamental, 2020; 23(2): 169290.

32. ZANDIFAR A, BADRFAM R. Iranian mental health during the COVID-19 epidemic. Asian Journal of Psychiatry, 2020; 51: e101990. 